\title{
Dynamic Optical Breast Imaging
}

National Cancer Institute

\section{Source}

National Cancer Institute. Dynamic Optical Breast Imaging. NCI Thesaurus. Code C53402.

A scan using red light instead of $\mathrm{x}$-rays to differentiate between benign and malignant conditions. It measures physiological changes in the breast when the breast is gently squeezed by an air filled bag. It is relatively comfortable (compared to a mammogram). 